\title{
EUROPEAN CENTRAL BANK FOOTPRINTS ON INFLATION FORECAST
}

\section{UNCERTAINTY}

\author{
Svetlana Makarova*
}

University College London, UK and Vistula University, Warsaw, Poland

Address: $\quad$ SSEES UCL, 16 Taviton Street, London, WC1H 0BW, UK

Tel: $\quad$ +44(0) 2076798821

Email: $\quad$ s.makarova@ucl.ac.uk

KEYWORDS: inflation ex-post uncertainty, monetary policy, country effects, inflation forecasting, euro area uncertainty.

\begin{abstract}
The finding of the paper shows the relative effectiveness of the 'one size fits all' policy of the European Central Bank. The paper provides strong evidence in favour of this by testing whether the monetary policy effects (footprints), found in inflation uncertainty converge to a common level. These footprints are measured as the fraction of the estimated policy-induced reduction in this uncertainty. The testing was conducted by applying a bootstrap-type test in a regression of the rate of growth of these fractions on their initial values, computed for 16 euro area countries. (JEL codes: C33, E52, E58).
\end{abstract}

The paper has an on-line supplementary annex.

\footnotetext{
* This paper was presented at 4th International Symposium in Computational Economics and Finance. I am very grateful for comments and suggestions received during this meeting. Financial support of the Opus 8 project HS4/04263 Modelling macroeconomic uncertainty, financed by the National Science Centre in Poland, and the ESRC/ORA project RES-360-25-0003 Probabilistic Approach to Assessing Macroeconomic Uncertainties are gratefully acknowledged. The paper was initiated during my research visit to the Bank of Estonia in 2014/2015. I am grateful to Dmitry Kulikov, Tairi Rõõm, Karsten Staehr and Lenno Uusküla for their comments on earlier versions of the paper. I am also grateful to Wojciech Charemza and the participants in the research seminar at the Bank of Estonia for stimulating discussions. I also thank the Editors and a Referee of the Economic Inquiry for deep and insightful comments on the previous versions of the paper. I am solely responsible for all remaining deficiencies.
} 


\section{INTRODUCTION}

One of the principal arguments for how the European Monetary Union can be economically effective in the allocative sense was made in 2005 in the speech by Ottmar Issing, then Chief Economist of the European Central Bank (ECB), at the International Research Forum on Monetary Policy. In this speech Issing (2005) reinforced his earlier point (Issing, 2001) in favour of the 'one size fits all' hypothesis for the single interest rate policy of the ECB. His main argument came from a reinterpretation of the real interest rate effect on growth when there are regional inflation differentials (see e.g. Caporale and Kontonikas, 2009). In the original interpretation, an interest rate determined by a single central bank would result in the real interest rate being relatively low in countries with high inflation, so stimulating growth, and relatively high in countries with low inflation, resulting in divergence in growth rates and increased uncertainty about inflation. Issing's counterargument was that investment decisions are based on ex-ante rather than ex-post real interest rates, or expected rather than historical inflation. If expected inflation is not idiosyncratic, then its dispersion between countries will not increase and no divergence in growth will occur.

Ten years after the speech the empirical evidence has been mixed. Some signs of inflation convergence were noticed five years after the creation of the euro (Mongelli and Vega, 2006; Busetti et al, 2007) and were confirmed later (Lopez and Papell, 2012), but the empirical support of real sphere convergence in the euro area is less evident. Although there are signs that there was convergence in output and unemployment before 2007, substantial divergence has been observed after that date (Estrada, Galí and López Salido, 2013; Monfort, Cuestas and Ordóñez, 2013). This makes it difficult either to disprove or to confirm Issing's hypothesis by evaluating the traditional convergence hypothesis.

However, convergence in levels of inflation does not necessarily imply that inflation uncertainty converges as well. This paper attempts to shed new light on the 'one size fits all' hypothesis and provide empirical evidence of a different type based on an evaluation of the effects 
of monetary policy on inflation uncertainty. The logic here is that Issing's (2005) conjecture that investment decisions are based on an ex-ante real interest rate reflecting the entire euro area implies that there is some uncertainty about future euro inflation. There may be some external factors, fiscal or political, which increase inflation uncertainty from its relatively low level. In this context the question arises of whether the economic policy of the euro area can successfully reduce the uncertainty by a similar proportion across countries. In a way this also relates to the conjecture of Arnold and Lemmen (2008) that, within the euro area, 'inflation uncertainty may increase in countries that have a smaller influence on ECB policy'.

The traditional approach to measuring inflation uncertainty is to calculate a measure of its variability and then evaluate changes in it over time (see e.g. Caporale, Onorante and Paesani, 2012; Lopez and Papell, 2012). As high inflation usually corresponds to higher dispersion of inflation, expost or ex-ante, periods of high inflation were historically associated with higher uncertainty. Other approaches are needed, however, in the current economic realities when the level of inflation is low. There is a growing literature discussing different approaches to defining and measuring inflation uncertainty and, more generally, macroeconomic uncertainty (see e.g. Giordani and Söderlind, 2003; Baker, Bloom and Davis, 2015; Jurado, Ludvigson and Ng, 2015; and Makarova, 2014, for a comprehensive discussion and overview). Inflation uncertainty is generally regarded as being detrimental to growth, either directly through the effect on long-term interest rates (Golob, 1994), or indirectly as a component of macroeconomic uncertainty, where it affects long-term transactional insurance and option costs (Bloom, 2014).

Verification of the hypothesis that ECB monetary policy is creating cross-country convergence in reducing inflation uncertainty is the main topic of this paper. It is important to note that convergence in reducing uncertainty resulting from a policy action is not the same as convergence in uncertainty itself nor, indeed, in levels of inflation. In this paper, inflation uncertainty is expressed by the dispersion of inflation forecast errors (see e.g. Clements, 2014). However, following Rossi and 
Sekhposyan (2015), further inference in this paper is based on the entire distribution of forecast errors rather than on its dispersion alone. It adapts the methodology proposed in Charemza, Díaz and Makarova (2015), where the weighted skew normal distribution (WSN) is fitted to pseudo expost forecast errors for annual inflation measured monthly. The parameters of the WSN can be interpreted as reflecting the monetary policy influence on uncertainty. This allows the relative effect of such a policy in reducing uncertainty to be evaluated. One measure of such effects is called the uncertainty ratio. If Issing's arguments are correct, the necessary condition for the 'one size fits all' hypothesis is that the uncertainty ratios across the euro area countries should converge to a common level, called the Common Uncertainty Reduction Effect in this paper (CURE), and convergence to the CURE is called CURE-convergence.

Bloom (2014) provides evidence that macroeconomic uncertainty is countercyclical to growth, and this is confirmed further by Henzel and Rengel (2017). Their findings support the real options theory (Bernanke, 1983; Brennan and Schwartz, 1985; McDonald and Siegel, 1986) and increasing of risk premia in times of uncertainty. As inflation uncertainty represents an essential part of macroeconomic uncertainty, divergence in inflation uncertainty in the countries of a currency union is likely to result in a divergence in growth in the real sector due to this countercyclicality. Therefore, if CURE-convergence exists, it documents the long-run tendency for monetary policy outcomes to be unified across countries.

The empirical model for testing CURE-convergence consists of regressing the rate of growth in the uncertainty ratio computed for different forecast horizons on the initial conditions. The construction of this is to some extent technically similar to that of fixed effect panel data models. However, the model is static by its nature as it has two cross-sectional dimensions, rather than crosssectional and time series dimensions. In this case the traditional standard errors of the estimates are not valid, as the distributions of the uncertainty ratios for different forecast horizons are usually not normal and might be highly interdependent. Consequently, it has been decided to apply the moving 
blocks bootstrap method here (Gonçalves, 2011). The main message of the paper is that despite the obstacles caused by the global financial crisis in 2007-2011 and the euro area debt crisis that has been bubbling away since 2009, monetary policy in the euro area provides strong and statistically significant support for CURE-convergence. If Issing's 'one size fits all' hypothesis is to be understood more broadly as the tendency of the effects of a single monetary policy on inflation forecast uncertainty across the euro countries to converge, this is what the CURE-convergence indicates.

The further structure of the paper is as follows. Section 2 discusses possible reasons for the divergence in inflation uncertainty given the convergence in levels. Section 3 applies some simple measures of inflation uncertainty and, without formal testing, illustrates the existence of such divergence in the euro area. Section 4 proposes a formal model for testing the convergence in reducing inflation uncertainty that is due to monetary policy and discusses its stochastic assumptions and estimation. Section 5 gives the main empirical results, Section 6 discusses their robustness, and Section 7 concludes.

\section{ECB MONETARY POLICY AND INFLATION UNCERTAINTY}

It is generally, albeit not universally, agreed that economic growth benefits from a reduction in macroeconomic uncertainty, a substantial component of which is inflation uncertainty (see e.g. Bloom, 2014; Vavra, 2014; Jurado, Ludvigson and Ng, 2015). There are numerous factors which cause inflation uncertainty to be different across the region. The heterogeneity of inflation uncertainty in a cross section of countries can be explained by the following main factors:

(i) A different level of inflation in each country. The level of inflation is often different between countries because of heterogeneous long-run factors like consumers' preferences, tax structures, asynchronous business cycles, employment structure, foreign trade diversification, the structure of credit channels and others. According to the Friedman-Ball hypothesis (Ball, 1992; Friedman, 1977), countries with a higher level of inflation should also have higher inflation uncertainty. The Friedman-Ball 
hypothesis is an alternative to the Cukierman-Meltzer (1986) hypothesis that positive causality goes from inflation uncertainty to inflation. In either case, it would be expected that high inflation uncertainty would be observed in times of high inflation and low inflation uncertainty in times of low inflation.

(ii) Various idiosyncratic factors which might not change the level of inflation, and so not trigger the Friedman-Ball effect, but may affect uncertainty in a direct way. The factors here include political uncertainty (for a theoretical treatment see Davig, Leeper and Walker, 2011), a lack of fiscal transparency or discipline, an unclear legal structure for long-term investment, unemployment threats, corrupt credit and microfinance channels, and others. These factors are predominantly country-specific, affecting uncertainty differently in different countries and resulting in heterogeneity in country-relative risk regimes (see e.g. Belke and Kronen, 2015; Delrio, 2016).

Regarding (i), there is strong empirical support for the Friedman-Ball and Cukierman-Meltzer hypotheses for the euro countries until 2010 (see e.g. Caporale, Onorante and Paesani, 2012). However, there is some econometric evidence suggesting that in at least some euro area countries inflation uncertainty has risen in recent years despite the continuously low level of inflation (Chowdhury and Sarkar, 2013). From more recent non-econometric accounts of growing macroeconomic uncertainty, which indicate inflation uncertainty without any expectation of a substantial rise in inflation itself (see e.g. European Commission, 2015), it becomes evident that the link between inflation and inflation uncertainty appears to have been broken, particularly between October 2011 and October 2013. This period coincides with the efforts of the European Central Bank to implement non-conventional monetary policy measures, in particular the credit support policy gradually introduced over time and announced in December 2011, and the policy of buying a substantial amount of government debt through the Outright Monetary Transactions programme, announced in July 2012 and phased out in 2014. This program contradicted, to an extent, the 'one size fits all' policy. As markets expected that it would be introduced, it stabilised inflation in some 
euro area countries but did not affect the dynamics of inflation uncertainty, as they were not embedded in the historical inflation records. Growing inflation uncertainty with a low level of inflation in this period indicates that the factors in (ii) were gaining in importance, particularly the political and fiscal uncertainty.

In the light of this, it might be interesting to find out not just how far inflation uncertainty in each country is reduced by ECB policy, but how effective this policy was in balancing uncertainty reduction across the euro area countries. Long-term success here should result in some convergence of measures for this reduction across countries.

\section{MEASURING UNCERTAINTY}

There are two widely used ways of measuring inflation forecast uncertainty. One, called the ex-ante approach, takes data from a panel of forecasts produced by surveys of individual forecasters and uses the dispersion between these forecasts as a benchmark measure of uncertainty ('uncertainty by disagreement'; see e.g. Bomberger, 1999; Lahiri and Sheng, 2010). This is sometimes accompanied by evaluations of uncertainty expressed by experts on the basis of their subjective knowledge (see e.g. Giordani and Söderlind, 2003; Patton and Timmermann, 2010). The other approach, known as ex-post, is based on analysis of past forecast errors and is often used by practitioners in central banks. Methods combining both the ex-post and ex-ante approaches have more recently been proposed (Lahiri, Peng and Sheng, 2014; Rossi, Sekhposyan and Soupre, 2016).

The main problem with the ex-ante approach is that the survey-based measures often suffer from cross-section and time series heterogeneity, time inconsistency and possible herd behaviour among individual forecasters (see e.g. Andrade and Bihan, 2013; Makarova, 2014; Clements, 2015; and, in the context of the forecasts produced by the ECB panel of forecasters, Abel et al. 2016). The concept of inflation uncertainty used here is ex-post forecast uncertainty based on the distribution of the past forecast errors of a forecasting model. The ex-post forecast uncertainty is easy to compute, and its interpretation is straightforward. It does not depend on the size or quality of the pool of 
forecasters and is free from political, emotional and sociological bias. However, such uncertainty is model-dependent, and quite often the number of observations used for computing the uncertainty measure of individual ex-post forecast errors is small.

To obtain observations on uncertainty, let us first define the concept of a baseline inflation forecast for time $t+h(h>0)$ as being publically available to all agents at time $t$ (inclusive of $t$ ). The series of such forecasts has been computed in the pseudo out of sample way, so they are obtained in continuously expanding windows (Stock and Watson, 2007), as:

$$
e_{t+h \mid t}=\pi_{t+h}-\hat{\pi}_{t+h \mid t}, \quad t=t_{0}, t_{0}+1, \ldots, T-h,
$$

where $h$ denotes the forecast horizon, $h=1, \ldots, H ; \pi_{t}$ is the observed headline HICP inflation at time $t ; \hat{\pi}_{t+h \mid t}$ is the trend inflation $h$-step ahead point forecast from the ARIMAGARCH model, estimated with data up to time $t$ (inclusive of $t$ ); $e_{t+h \mid t}$ are the trend inflation forecast errors of the forecast made in time $t$ for $t+h ; T$ is the total length of the data series; and data for the period from 1 to $t_{0}$ (inclusive) are used for the initial model estimation. It is further assumed that this forecast is a 'common knowledge' forecast that does not constitute information relevant for monetary policy but can be improved upon by ECB forecasters.

Evidently the choice of model used for computing the baseline forecast is, to an extent, arbitrary, and selecting another model might lead to a different series of baseline forecast errors being obtained. It has been decided to use the ARIMA-GARCH model as the forecasting tool, for two main reasons. The first is related to its interpretation. In the concept of monetary policy-induced uncertainty applied in this paper, the point forecasts for which errors are subsequently computed represent a forecasted 'common knowledge' (trend) inflation, where the autoregressive models perform well (see Clark and Doh, 2014). The underlying assumption is that as such forecasts are commonly known, only improvements in them might influence monetary policy decisions. This can be supported by Phelps and Taylor (1977), Fisher (1977), and Orphanides and Williams (2005), and 
on game-theoretical grounds by Morris and Shin, (2002). The second reason for using the ARIMAGARCH model is its simplicity, flexibility, low computational costs and, above all, the fact that its forecasting properties are comparable with those of more complex multivariate models and stochastic volatility models in its forecasting properties (see e.g. Bjørnland et al., 2012; Buelens, 2012; Clark and Ravazzolo, 2015; Mitchell, Robertson and Wright, 2015).

A single observation on the $h$-steps ahead uncertainty in time $t$ is defined as:

$$
u_{t, h}=e_{t+h \mid t}\left(\sqrt{\sigma_{t, h}^{2} / \hat{\sigma}_{t+h \mid t}^{2}}\right)
$$

where $\hat{\sigma}_{t+h \mid t}^{2}$ is the $h$-step ahead forecast of GARCH conditional variance and $\hat{\sigma}_{t, h}^{2}$ is the unconditional variance of $e_{t+h \mid t}$. Removing the time-dependent second-order effects from the forecast errors $e_{t+h \mid t}$ by scaling them by the conditional variance in (2) is in line with the understanding of forecast uncertainty, which does not include the forecastable variation (see Clements, 2014). Consequently, the monetary policy affects only the part of total uncertainty expressed by forecast errors, which is unforecastable by the first and second moments of the model. The ex-post forecast uncertainty at time $t\left(t=t_{0}+h+\Delta-1, \ldots, T\right)$ for forecast horizon $h$ is defined as the root mean square error (RMSE) of $u_{t, h}$ over the moving time windows of bandwidth $\Delta$ that starts from $t_{0}+h$ and runs to $T-\Delta+1$.

The baseline forecast errors (1) have been obtained by estimating the $\operatorname{ARIMA}(p, 1,1)$ GARCH $(1,1)$ models by the maximum likelihood method using monthly data on the annual HICP inflation. ARIMA-GARCH models with more complex lags structure have also been tried and discarded as being not more accurate than simpler models, or due to numerical problems in estimation. The computations have been made for 16 of the 18 euro area countries, excluding Cyprus and Slovakia, for which there have been convergence problems in the estimation due to the small number of observations. Data for all countries and also for the entire euro area have been 
downloaded from Eurostat. The data series for all the countries end in November 2014 and start between January 1991 and January $1996^{1}$. Detailed data spans and country abbreviations are given in Appendix A. Full sample inflation for all the countries has been found to be integrated of order one (details of the unit root testing, which allows for the existence of structural breaks, are available in On-line Annex, Part C). Therefore the models have been estimated in first differences). The lag length of the ARIMA process has been chosen in each recursion as the minimum for which autocorrelation of the residuals (up to order 12 ) is jointly insignificant at the $5 \%$ significance level. The first recursion uses the first $20 \%$ of the observations in each series, but not more than 80 . Column 5 in Table A1 (see Appendix A) shows the numbers of one-step ahead forecasts made for each country and also indicates the date that is associated with the first one-step ahead forecast error for each country. For the two-step ahead forecast errors the start date is one month later, and so forth. For each forecast, the ex-post forecast errors given by (1) and observations on uncertainty (2) have been calculated. Finally, for each set, the RMSE of $u_{t, h}$ has been computed in rolling windows as described above as the measure of uncertainty. With identical window bandwidth of $\Delta=120$ for calculating RMSE for different countries and different forecast horizons, it gives a different start date for the RMSEs and a different number of observations (details are shown in Table A1, column 6).

Figure 1 compares HICP inflation for Germany and Greece (left panel) and France and Italy (right panel), from 2000m01 until 2014m11. Figure 2 plots the corresponding RMSEs of $u_{t, h}$ for these countries for $h=1$. Figure 1 indicates the presence of pairwise inflation convergence in levels of HICP inflation for the pairs of countries shown. This is in line with the Monfort, Cuestas and Ordóñez (2013) conjecture of the existence of different convergence clubs in the euro area. It appears that Germany and Greece are in different convergence clubs and Italy and France are in the same one. However, Figure 2 shows that there is an evident divergence in inflation uncertainty for the same

\footnotetext{
${ }^{1}$ For some of the countries that joined euro area recently, e.g. Estonia and Latvia, the HICP index for the beginning of this period was recalculated retrospectively and published by Eurostat.
} 
period and the same countries. Similar finding has been made by Rossi and Sekhposyan (forthcoming). For Germany and France lower inflation is associated with lower uncertainty, thus providing strong evidence in favour of the Friedman-Ball or Cukierman-Meltzer hypotheses. For Greece and Italy, however, it is the opposite as low inflation corresponds to increased uncertainty.

Given the purpose of this paper, there is no need to pursue by formal testing the convergence of inflation and inflation uncertainty any further. More evidence in favour of such divergence can be drawn from the time series of the RMSEs given in the Supplementary Materials in the On-line Annex, Part A (Figures S1.a-S1.c for inflation and Figures S2.a-S2.c and S3.a-S3.d for RMSEs for the forecast horizons $h=1$ and $h=12$ respectively). While we might observe convergence in levels of inflation in the euro area, there is clearly a divergence in inflation uncertainty. Developing from the discussion in Section 2 above it can be argued that factors beyond the Friedman-Ball or Cukierman-Meltzer hypotheses are responsible for this divergence. It can be conjectured that these factors could be related to a lack of fiscal discipline. Detailed analysis of this is, however, outside the scope of this paper.

\section{FIGURE 1}

Annual HICP inflation from 2000m01 until 2014m11 for Germany, Greece, France and Italy (data source: Eurostat).
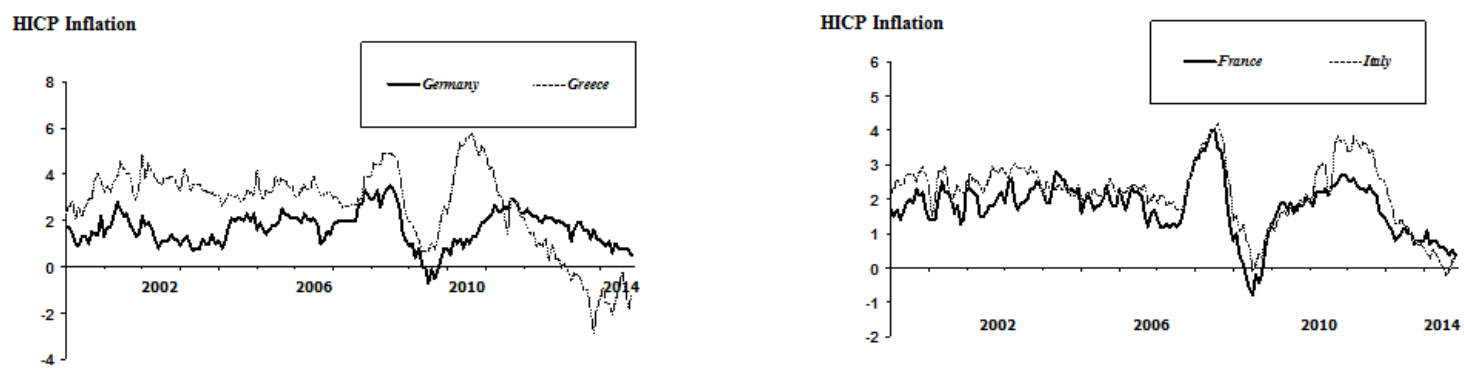
Forecast uncertainty (RMSE): Germany, Greece France and Italy, forecast horizon $h=1$.
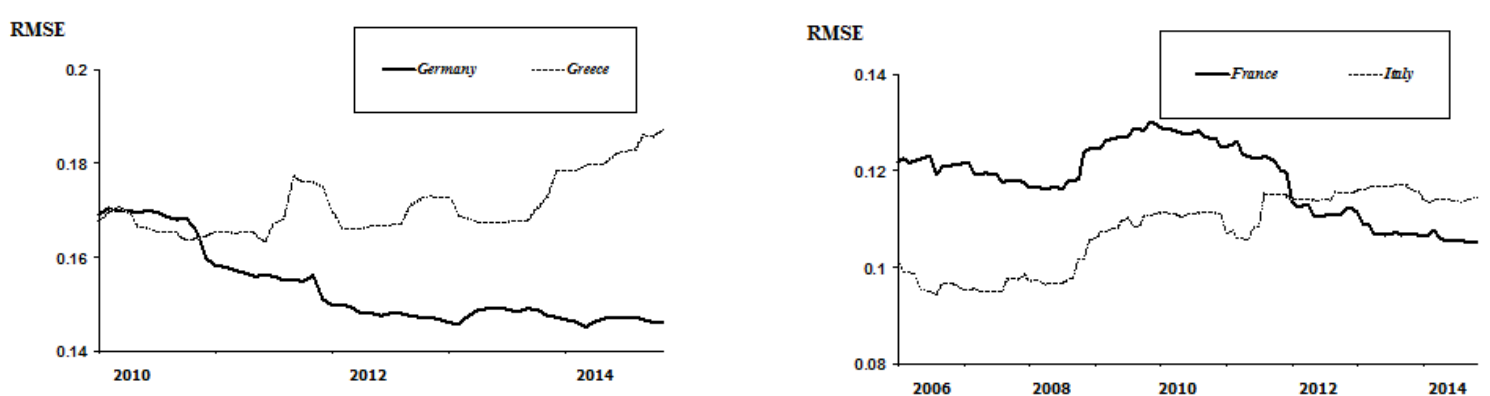

Comments to Figure 2: The RMSEs are computed in the recursively updated rolling windows of length $\Delta=120$ as the mean root squared ARIMA-GARCH scaled forecast errors as defined by (1) and (2). (see Appendix A for the definition of sample length and initial recursions for each country).

\section{UNCERTAINTY AND MONETARY POLICY}

If monetary policy is to be effective in reducing uncertainty, the RMSEs of the $u_{t, h} \mathrm{~s}$, should be smaller than the RMSEs computed for the hypothetical uncertainty that is free from the effects of monetary policy. Unlike the $u_{t, h} \mathrm{~s}$, this uncertainty is unobservable in the sense that it cannot be retrieved from forecast errors. Strictly speaking, it would have been observable if the monetary policy had not been implemented, as in that case it would coincide with $u_{t, h}$. However, under the additional assumption that for each county and each horizon $h$, uncertainty $u_{t, h}$ follows the weighted skew normal distribution (WSN) it is possible to derive an approximation of the distribution of this uncertainty and therefore to estimate the ratio of its variance to $\operatorname{RMSE}\left(u_{t, h}\right)$. The WSN random variable $U$ used for such an approximation is defined by:

$$
U=X+a \cdot Y \cdot I_{Y>m}+b \cdot Y \cdot I_{Y<k}, \quad(X, Y) \sim N\left(\left[\begin{array}{l}
0 \\
0
\end{array}\right],\left[\begin{array}{cc}
\sigma^{2} & \rho \sigma^{2} \\
\rho \sigma^{2} & \sigma^{2}
\end{array}\right]\right),
$$


where $I_{\{\bullet\}}$ is the indicator function of a set $\{\bullet\}, a, b, m, k \in \mathbb{R}$, and $-1<\rho<1$, while $X$ is the random component that is unpredictable from the baseline forecast. As the baseline forecast is made using common information that is publically available, $X$ is not predictable if only publically available information is used. However, the monetary policy decision makers might have some partial knowledge represented by $\rho>0$. The random variable $Y$ represents forecasts (strictly speaking, corrections to the baseline forecast) made by the ECB forecasters and delivered to the Governing Council of the ECB. If these forecasts show that inflation exceeds the thresholds, that is $Y>m$ or $Y<k$, the Governing Council undertakes either an anti-inflationary policy with strength $a$, or a proinflationary policy with strength $b$ respectively. In this setup the distribution defined by (3) has natural economic interpretation if $a<0, b<0, m>0$ and $k<0$. This explanation is fairly simplified, especially in the context of ECB action based on a set of inflation forecasts from different countries rather than a single, homogeneous signal about inflation (for a more detailed explanation see Charemza, Díaz and Makarova, 2015). As the WSN distribution is fitted for each country separately, its parameters $a$ and $b$ correspond to the anti-inflationary and pro-inflationary country effects of the single ECB decision. As the variable $Y$ is not observable, the thresholds $m$ and $k$ are also not observable.

Variance of $X$ represents the 'public' uncertainty, which is the uncertainty of those agents who do not have access to the additional forecasts represented by $Y$. It seems reasonable to assume that the dispersion of the additional forecast represented by $Y$ cannot be greater than the dispersion of 'public' uncertainty, as this would imply that the ECB forecasters are less informed than the agents. It can be smaller, but how well the forecasters are 'informed' has already been included in the model through the correlation coefficient $\rho$. That this dispersion might be smaller than the dispersion of 'public' uncertainty is captured to some extent by the magnitude of the coefficient $\rho$ in equation (3) which expresses the competence of the ECB forecasters. The smaller the true dispersion of $Y$ is 
relative to the dispersion of $X$, the smaller the correlation coefficient $\rho$ is. It was therefore assumed that the variances of $X$ and $Y$ are identical and equal to $\sigma^{2}$.

The WSN distribution defined by (3) is parametrised by six parameters. In order to increase the efficiency of estimation and to avoid identification problems, it has been decided to reduce the number of estimated parameters to three, namely $\alpha, \beta$ and $\sigma$. The ECB forecast signals are seen as large enough to act upon if they exceed one standard deviation, so in the estimation, $\hat{m}$ and $\hat{k}$ are set to $\pm \hat{\sigma}$, where $\hat{\sigma}$ denotes the estimate of $\sigma$. The parameter $\rho$ reflects how much predictability is left in $X$ and at the same time it indicates how accomplished the forecasts in $Y$ are. If $X$ is completely unpredictable or if the ECB forecasters who deliver $Y$ are ignorant, then $\rho=0$. If $X$ is fully predictable by the ECB forecasters, then $\rho=1$. Moreover, for the thresholds-symmetric case when $k=-m$, the variance of the WSN distribution decreases monotonically up to the point given by the constraint $-2 \rho=\alpha+\beta$. Consequently, low values of $\rho$ implicitly constrain the strength of monetary policy in reducing uncertainty. A sensible choice seems to be $\rho=0.75$, which reflects reasonable degree of competence of the ECB forecasters and potential policy strength. Other values of $\rho$ have also been tried in the robustness check but without much effect on the outcome.

The estimates of $a, b$ and $\sigma$ in (3) are obtained using data on $\left\{u_{t, h}\right\}$ separately for each country and each horizon $h$, in rolling windows of length $\Delta=120$. For each country and each forecast horizon (with country and forecast horizon indices omitted to simplify the notation) this gives the series of estimates $\{\hat{a}(j)\},\{\hat{b}(j)\}$ and $\{\hat{\sigma}(j)\}$ where the $j$-th estimate corresponds to the period between $\left(t_{0}+h+j-1\right)$ and $\left(t_{0}+h+j+\Delta-2\right)$, when $j=1, \ldots,\left(T-t_{0}-h-\Delta+2\right)$. For clarity of notation, each estimate is assigned to the right end of the interval it corresponds to and is re-denoted $\quad$ as $\quad \hat{a}_{s} \equiv \hat{a}(j), \hat{b}_{s} \equiv \hat{b}(j), \quad \hat{\sigma}_{s} \equiv \hat{\sigma}(j), \quad$ where $\quad s=t_{0}+h+j+\Delta-2$ $\left.s=t_{0}+h+\Delta-1, \ldots, T\right)$. The random variable, which is WSN-distributed with these parameters, is 
denoted as $U_{s, h}$ (the country index is omitted for simplicity). The estimation method used here is the simulated minimum distance estimation (SMDE) method (Charemza et al., 2012). Appendix B contains a brief description of the SMDE method. The aggregated results of fitting the WSN distribution to one-step ahead uncertainties are in the On-line Annex, Part D.

The random variable $V$ that approximates the distribution of the hypothetical uncertainty that is free from the effects of monetary policy can be recovered from the WSN distribution fitted to expost forecast errors $u_{t, h}$ (separately for each country and each forecast horizon $h$ ) by removing from $U$ most of the predictable components, some of which are still left due to the possible monetary policy feedback, so that

$$
V=U-E(X \mid Y)=U-\rho Y=X-\rho Y+a \cdot Y \cdot I_{Y>m}+b \cdot Y \cdot I_{Y<k} .
$$

The random variable $V$ defined by (4) above is also of the WSN type, and its parameters and thus the variance of $V, \operatorname{Var}(V)$, can be expressed via the parameters of $U$, meaning via $a, b, m, k \rho$ and $\sigma$. This is done in rolling windows (again, for each country and each forecast horizon $h$ separately) that correspond to the estimates $\{\hat{a}(j)\},\{\hat{b}(j)\},\{\hat{\sigma}(j)\}$, where $s=t_{0}+h+j+\Delta-2, \quad$ ( $\left.s=t_{0}+h+\Delta-1, \ldots, T\right)$. The ratio of the variance of the corresponding $V$ to the RMSE of the observed ex-post errors $u_{t, h} \mathrm{~s}$ can then be computed for each window. This ratio is called the uncertainty ratio and is defined as (see Charemza, Díaz and Makarova, 2015):

$$
\mathrm{UR}_{i, h}(s)=\operatorname{Var}(V) / \operatorname{RMSE}(U), \quad h=1,2, \ldots, H,
$$

where $i$ stands for the country $(i=1, \ldots, 16)$, and $s=t_{0}+h+\Delta-1, \ldots, T . \mathrm{UR}_{i, h}(s)$, referred further simply as UR, represents an approximation of the fraction of uncertainty reduced as the result of action taken in response to the forecast signals based on the information in $Y$. In other words, it shows the footprints of monetary policy in the uncertainty. For simplicity of notation, country 
indicators (i) and the window which the uncertainty ratio corresponds to $(s)$, are omitted from the right-hand side of (5). It is also worth noting that there are different numbers of observations on inflation for different countries as the data begin at different points in time, which means that the first time moment for which the uncertainty ratio can be computed $s=t_{0}+h+\Delta-1$ is different for each country. This is accounted for in the further empirical analysis.

The uncertainty ratio $\mathrm{UR}_{i, h}(s)$ defined by (5) can be expressed via $\rho$, set to 0.75 for each country and each forecast horizon, the estimated parameters $\{\hat{a}(j)\},\{\hat{b}(j)\}$ and $\{\hat{\sigma}(j)\}$, and the thresholds $\hat{m}$ and $\hat{k}$, which are set to $\pm \hat{\sigma} .^{2}$ The explicit formula is given in Appendix $C$. The immediate interpretation of the uncertainty ratio, UR, that follows from (5) is that if the policy is effective in reducing uncertainty than the UR is greater than unity.

Table 1 summarises and compares the aggregated URs and RMSEs separately for the countries investigated, and also for the entire euro area. Aggregation has been made in the following way for each country and for the euro area. First, the discounted sums across forecast horizons were obtained with the Samuelson time discount function applied (see Al-Nowaihi and Dhami, 2014, for a discussion, behavioural interpretation and comparison with other concepts of time discounting). The discount weights were set first in a decaying way, with the higher weights given to short-horizon forecasts, and then were reversed, with higher weights for long horizons. These alternative ways of aggregating correspond to assigning particular importance to short-run and long-run uncertainty respectively, and are analogously called 'short' and 'long' aggregation. Next, arithmetic averages across windows were computed. The table shows that for all countries the averaged and discounted URs are greater than one, suggesting the EU monetary policy is effective overall in reducing uncertainty. Short-aggregated URs are higher than long-aggregated ones, which means that the URs for shorter horizons are generally greater than the corresponding URs for longer horizons, indicating

\footnotetext{
${ }^{2}$ Other settings have also been used. The results do not differ markedly from those presented here.
} 
better policy effects in reducing uncertainty for shorter horizons. The RMSEs for Estonia and Latvia are disproportionally higher than those for the other countries, which is clearly a result of the high inflation which occurred in these countries in early periods ${ }^{3}$. There is a positive and significant at the $10 \%$ significance level (or smaller) Spearman and Kendall rank correlation between the URs and RMSEs. This correlation is evident regardless of whether the outlier countries, Estonia and Latvia, are included or excluded. As this suggests that the URs are increasing faster as the RMSEs increase (see (5) above), it can be interpreted as observing better efficiency in reducing inflation uncertainty in countries where the levels of uncertainty were high, rather than the opposite.

TABLE 1

Aggregated uncertainty ratios (UR) and uncertainty (RMSE of scaled forecast errors).

\begin{tabular}{lcccc}
\hline & \multicolumn{2}{c}{ Short aggregation } & \multicolumn{2}{c}{ Long aggregation } \\
Country & UR & RMSE & UR & RMSE \\
\hline Austria & 1.098 & 0.3617 & 1.076 & 0.5401 \\
Belgium & 1.133 & 0.7103 & 1.085 & 1.0620 \\
Germany & 1.139 & 0.2932 & 1.084 & 0.4297 \\
Estonia & 1.109 & 2.2260 & 1.087 & 3.8060 \\
Spain & 1.111 & 0.7089 & 1.080 & 1.0270 \\
Finland & 1.073 & 0.3721 & 1.072 & 0.5663 \\
France & 1.106 & 0.3851 & 1.078 & 0.5655 \\
Greece & 1.124 & 0.4792 & 1.083 & 0.7077 \\
Ireland & 1.187 & 0.7202 & 1.195 & 1.2260
\end{tabular}

\footnotetext{
${ }^{3}$ All countries that are joining the euro area must satisfy the Maastricht criteria and, in particular, have coordinated monetary policy and participated in the exchange rate mechanism (ERM II) for at least two years prior to joining the euro area. As this gives similarity in monetary policies, countries that joined the common currency area relatively late, like Estonia and Latvia, were included in the sample.
} 


$\begin{array}{lllll}\text { Italy } & 1.106 & 0.3669 & 1.079 & 0.5718 \\ \text { Luxembourg } & 1.150 & 0.7101 & 1.122 & 0.9760 \\ \text { Latvia } & 1.198 & 3.8680 & 1.148 & 7.0740 \\ \text { Malta } & 1.123 & 0.8093 & 1.083 & 1.1400 \\ \text { Netherlands } & 1.134 & 0.3481 & 1.102 & 0.5550 \\ \text { Portugal } & 1.125 & 0.5500 & 1.084 & 0.8468 \\ \text { Slovenia } & 1.162 & 0.7417 & 1.094 & 1.1200 \\ \text { EURO } & \mathbf{1 . 1 1 3} & \mathbf{0 . 3 4 5 6} & \mathbf{1 . 0 8 0} & \mathbf{0 . 5 3 6 6}\end{array}$

Comments to Table 1: The RMSEs are computed separately for each forecast horizon from 1 to 18 in the recursively updated rolling windows of length $\Delta=120$ as the mean root squared ARIMA-GARCH scaled forecast errors as defined by (1) and (2). These RMSEs are then averaged across windows and aggregated across forecast horizons using the Samuelson discount function (short aggregation) and the reverse discount function (long aggregation). The individual URs are computed using the WSN estimated parameters from (4), (5) and (C1) then aggregated similarly to RMSEs (see Appendix A Table A1 for the description of sample period for each country).

Figure 3 shows the time paths of the development of the uncertainty ratio for $h=1$ for selected euro area countries: Germany and Greece (left panel) and France and Italy (right panel) for the same periods as in Figure 2 in Section 3, which is $2010 \mathrm{~m} 01$ to $2014 \mathrm{~m} 11$. Apart from two turbulent periods for France in the beginning of 2012 and the end of 2013, the URs for all four countries are above unity. The dynamics of the URs for the other euro area countries are less clear, indicating periods of different gains in the sense of reductions in uncertainty policy. For most of these countries substantial volatility and heterogeneity of URs were before 2012. After 2012, there is a general tendency of converging towards the level of UR computed for the entire euro area, with the exception of Luxembourg, Netherlands and Ireland, which URs have been declining, reaching levels close to unity and below for 2014-2015, and Latvia with the opposite trend (see Figures S4.a-S4.c in On-line Annex, Part A). 


\section{FIGURE 3}

Uncertainty ratio (UR) for selected euro area countries, forecast horizon $h=1$.

UR

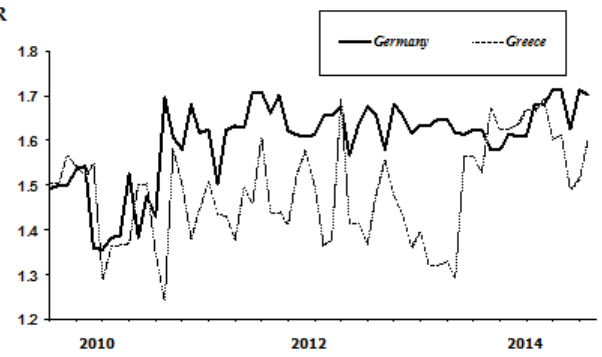

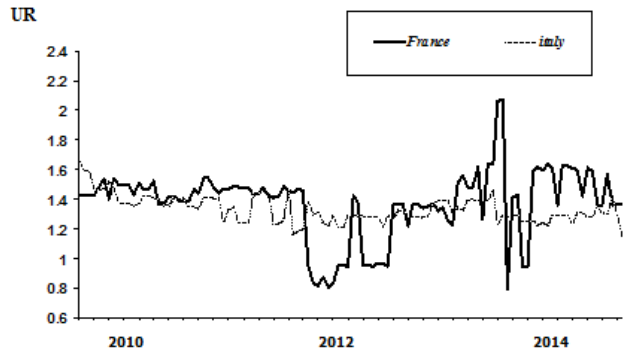

Comments to Figure 3: The URs are computed from (5) and (C1) using the WSN parameters estimated by the SMDE method with the minimum Hellinger distance criterion using the scaled forecast errors obtained from (1) and (2). The computations are made in rolling windows with constant length $\Delta=120$.

It can also be noted that periods of relative success in reducing uncertainty for some of the countries correspond to periods of ineffectiveness for others. This seems to be quite natural. Countries may have different capacity for inflation uncertainty reduction as there are various idiosyncratic factors (see Section 2). It is not realistic to expect that the ECB policy will be effective in reducing uncertainty in the absolute sense by leading to an increase in the UR in all countries. A more plausible hypothesis could therefore be relative policy effectiveness through the convergence of the URs to a common level across the euro area countries.

\section{THE CURE-CONVERGENCE TEST}

To test the CURE-convergence hypothesis formally, let us consider a hypothetical level of UR that is identical for all the euro area countries. Convergence to such a UR is called the common uncertainty reduction effect and is abbreviated as CURE-convergence. In order to test for it, the following model has been estimated:

$$
g_{i, h}=\alpha_{i}+\beta \cdot \mathrm{UR}_{i, h}^{0}+x_{i, h}^{\prime} \gamma+\varepsilon_{i, h}, \quad i=1,2, \ldots, N, \quad h=1,2, \ldots, H,
$$


where $g_{i, h}$ is the average rate of growth of $\mathrm{UR}_{i, h}$ for country $i$ and forecast horizon $h$ over the period that is common to all countries starting on $2010 \mathrm{~m} 12$ for $h=1,2011 \mathrm{~m} 01$ for $h=2$ etc. All periods end in $2014 \mathrm{~m} 11$. The number of countries is $N=16$ and the number of forecast horizons is $H=18$ ${ }^{4} \mathrm{UR}_{i, h}^{0}$ is the initial level of $\mathrm{UR}_{i, h} ; \alpha_{i}$ s denote country-specific effects resulting from the factors discussed in Section 2 that affect the uncertainty ratio in individual countries and are assumed to be constant for each forecast horizon $h ; \beta$ is the coefficient which decides the CURE-convergence hypothesis, and more specifically, the CURE-convergence hypothesis is confirmed if $\beta$ is significantly negative. Vector $x_{i, h}$ is a $q \times 1$ vector of other variables on which the rates of growth of $\mathrm{UR}_{i, h}$ are conditioned with the corresponding vector of parameters $\gamma$, and $\varepsilon_{i, h}$ is the error term. Other specifications that include time-specific effects have also been tried, but these effects turned out to be statistically insignificant. In the model discussed below, the variables in $x_{i, h}$ contain products of $\mathrm{UR}_{i, h}^{0}$ and country dummies for Germany, Spain, France, Greece and Italy or horizon dummies for $h=1,2,3,6$.

Model (6) resembles the simple fixed-effect panel data growth model (Barro and Sala-i-Martin, 1995; Islam, 1995). In fact, model (6) is not a panel data model as the dependence is on the forecast horizon rather than on time. Hence it is a static cross-section model in its essence. However, the possible mutual dependence of multi-level forecasts is expected to be transmitted into the dependence of URs for different forecast horizons, which might create effects similar to that of the time effect in panel data models with heteroscedasticity and autocorrelation.

Further difficulties in testing arise because the distributions of $\varepsilon_{i, h}$ are likely to be nonnormal, heteroscedastic and 'autodependent', meaning they have dependence on different forecast horizons, possibly nonlinear, due to the non-normality of the residuals. This might

\footnotetext{
${ }^{4}$ It has been decided to limit the forecast horizon to 18 rather than 24 because of numerical problems in estimating the WSN parameters using a relatively small sample in rolling windows of 120 (see Appendix B).
} 
affect the estimates of the standard errors of $\varepsilon_{i, h}$ and consequently distort the testing results for the parameters. To ease this problem, the standard errors and consequently the $p$-values of the significance statistics have been estimated by applying the moving blocks bootstrap, MBB (Gonçalves, 2011), for data ordered by forecast horizon.

Following Gonçalves, the MBB algorithm consists of the following steps:

(1) For each $h$, stack observations on $g_{i, h}$ and $z_{i, h}=\left[U R_{i, h}^{(0)}, x_{i, h}^{\prime}\right]^{\prime}$ in a $N \cdot(p+2)$ vector $\Gamma_{h}=\left[g_{1, h}, z_{1, h}^{\prime}, g_{2, h}, z_{2, h}^{\prime}, \ldots, g_{I, h}, z_{I, h}^{\prime}\right]^{\prime}$, where $p$ denotes the number of regressors in $x_{i, h}$.

(2) Define block length $\ell=H / \kappa$ such that $1 \leq \ell \leq H$ and $H$ is divisible by an integer $\kappa$. Then create a block $B_{j}$ of $\ell$ consecutively stacked vectors of $\Gamma_{h}$ as $\mathrm{B}_{j}=\left[\Gamma_{j}, \Gamma_{j+1}, \ldots, \Gamma_{j+l-1}\right], j=1,2, \ldots T-\ell+1$. If $\kappa=T$, so if $\ell=1$, MBB becomes a standard i.i.d. bootstrap on data ordered by forecast horizon. If $\kappa=1$, so if $\ell=H$, no bootstrap is performed. The length recommended by Gonçalves (2011) for the blocks of samples with a time dimension close to 25 (in this case the forecast horizon dimension) is $\ell \approx 2.5$. Because of this, it has been decided to use $\ell=2$, as the number of forecast horizons is equal to 18 . The results for $\ell=3$, not reported here, are very similar.

(3) From a set of $H-\ell+1$ of such overlapping blocks, draw a uniformly distributed sample with replacement on $\{1,2, \ldots, l\}$ of $\kappa$ of them and, for this pseudo (bootstrapped) sample, estimate the parameters in (6). Due to the pseudo-sample nature rather than true sample nature of the draws, the ordinary Student- $t$ ratios are not valid, as the OLS covariance matrix of the residuals is inconsistent. Gonçalves (2011) provides a formula for the long-run asymptotic covariance matrix for MBB pseudo-samples, which can be used for computing Student- $t$ ratios in each draw. Such estimates of the covariance matrix are robust to cross-sectional and between-forecast horizon dependence of 
unknown form. The robustness does not depend on the assumption of normality for the error terms.

(4) Repeat (3) many times, collect Gonçalves' $t$-ratios, and use them for computing $p$ values for particular estimates. Note that the direct estimate of standard errors of the parameters obtained across the pseudo-sample is not valid. In the results presented here the total number of valid bootstraps, excluding the cases where singularity has been obtained, is set at 10,000 .

Table 2 provides a summary of the output for the estimates of model (6) under various specifications of $x_{i, h}$. The notation here is as follows. Products of $\mathrm{UR}_{i, h}^{0}$ and country dummies are denoted as $\mathrm{UR}^{0} * \mathrm{AA}$, where $\mathrm{AA}$ is the two-digit country code explained in Appendix A. Products of $\mathrm{UR}_{i, h}^{0}$ and horizon dummies are denoted as $\mathrm{UR}^{0} * h \mathrm{NN}$, where $\mathrm{NN}$ denotes an integer indicating the forecast horizon of between 1 and 18 . The HAC $p$-values for the ordinary non-bootstrapped fixedeffects OLS estimates and the MBB $p$-values for $l=2$ are given beneath the parameter estimates in the first and second rows respectively ${ }^{5}$. Country effects $\alpha_{i}$ are jointly significant in all models, and so for clarity of presentation they are not included in Table 2 .

The results given in Table 2 indicate, not surprisingly, that omitting the products of $\mathrm{UR}_{i, h}^{0}$ and country/forecast horizon dummies causes substantial underestimation of the speed of the convergence parameter $\beta$, in comparison with all the other specifications or models. The estimates of $\beta$ for all the other models (except Model 6) are close to each other, negative and significant. This suggests the specification is robust in its estimates in models with the $\mathrm{UR}_{i, h}^{0}$ and dummy product

\footnotetext{
${ }^{5}$ Computations have been made using GAUSS. The procedures for computing the HAC standard errors are written by Seung Chen Ahn and available at http://www.public.asu.edu/ miniahn/ecn726/ecn_726.htm\#syllabus. Other codes used here are available on request.
} 
variables and also strongly supports the existence of CURE-convergence in the period between December 2010 and November 2014. Throughout the models, the cross-effects of $\mathrm{UR}_{i, h}^{0}$ are stable and significant, as are the country effect variables for Germany and Greece, which are two extreme countries in the euro area. They are also positive, though smaller than the corresponding $(-\beta)$ estimates, which suggests slower convergence in the effects of ECB monetary policy in reducing uncertainty at the opposite ends of the spectrum for the euro area. For the middle-ground countries like France and Italy, the cross-effects are small and insignificant. This is also true for other countries in the euro area (not reported here) except for Spain, which exhibits a strongly positive and significant effect in all the specifications reported here. However, the magnitude of the estimated coefficient for the cross-effect for Spain is similar to that of $(-\beta)$, so its overall effect on the CUREconvergence is likely to be neutral. 


\section{TABLE 2}

Summary of models' estimation.

Dependent variable: $g_{i, h}$, average growth rate of uncertainty ratio for country $i(i=1, \ldots, 16)$ and forecast horizon $h(h=1, \ldots, 18)$. Total number of observations: 288 .

\begin{tabular}{|c|c|c|c|c|c|c|}
\hline regressor & Model (1) & Model (2) & Model (3) & Model (4) & Model (5) & Model (6) \\
\hline \multirow[t]{3}{*}{$\mathrm{UR}_{i, h}^{0}$} & $-1.106^{*}$ & $-1.795^{*}+$ & $-1.778 *+$ & $-1.786^{*}+$ & $-1.761 *+$ & $-1.357^{*}+$ \\
\hline & $(0.018)$ & $(0.007)$ & $(0.007)$ & $(0.007)$ & $(0.007)$ & $(0.006)$ \\
\hline & $(0.330)$ & $(0.000)$ & $(0.000)$ & $(0.000)$ & $(0.000)$ & $(0.042)$ \\
\hline \multirow[t]{3}{*}{$\mathrm{UR}^{0} \times \mathrm{DE}$} & & $1.464^{*}+$ & $1.474^{*}+$ & $1.479 *+$ & $1.523 *+$ & $1.661 *+$ \\
\hline & & $(0.004)$ & $(0.004)$ & $(0.008)$ & $(0.005)$ & $(0.001)$ \\
\hline & & $(0.000)$ & $(0.000)$ & $(0.000)$ & $(0.000)$ & $(0.003)$ \\
\hline \multirow[t]{3}{*}{$\mathrm{UR}^{0} \times \mathrm{ES}$} & & $1.871^{*}+$ & $1.912^{*}+$ & $1.919 *+$ & $2.010^{*}+$ & $2.490 *+$ \\
\hline & & $(0.010)$ & $(0.011)$ & $(0.023)$ & $(0.012)$ & $(0.000)$ \\
\hline & & $(0.000)$ & $(0.006)$ & (0.011) & $(0.001)$ & $(0.000)$ \\
\hline \multirow[t]{3}{*}{$\mathrm{UR}^{0} \times \mathrm{FR}$} & & & & 0.463 & & \\
\hline & & & & $(0.256)$ & & \\
\hline & & & & (0.119) & & \\
\hline \multirow[t]{3}{*}{$\mathrm{UR}^{0} \times \mathrm{GR}$} & & $1.377^{*}+$ & $1.385^{*}+$ & $1.391^{*}+$ & $1.444^{*}+$ & $1.671 *+$ \\
\hline & & $(0.011)$ & $(0.011)$ & $(0.019)$ & $(0.012)$ & $(0.001)$ \\
\hline & & $(0.042)$ & $(0.026)$ & $(0.024)$ & $(0.000)$ & $(0.000)$ \\
\hline \multirow[t]{3}{*}{$\mathrm{UR}^{0} \times \mathrm{IT}$} & & & & -0.567 & & \\
\hline & & & & $(0.306)$ & & \\
\hline & & & & $(0.283)$ & & \\
\hline \multirow[t]{3}{*}{$\mathrm{UR}^{0} \times h 1$} & & $0.210+$ & $0.202+$ & $0.203+$ & $0.180+$ & \\
\hline & & $(0.173)$ & $(0.185)$ & $(0.205)$ & $(0.221)$ & \\
\hline & & $(0.000)$ & $(0.000)$ & $(0.002)$ & $(0.002)$ & \\
\hline \multirow[t]{3}{*}{$\mathrm{UR}^{0} \times h 2$} & & $0.146 *+$ & $0.143 *+$ & $0.140 *+$ & $0.133^{*}+$ & $0.107^{*}$ \\
\hline & & $(0.001)$ & $(0.002)$ & $(0.004)$ & $(0.004)$ & $(0.014)$ \\
\hline & & $(0.001)$ & $(0.001)$ & $(0.002)$ & $(0.002)$ & (0.379) \\
\hline
\end{tabular}




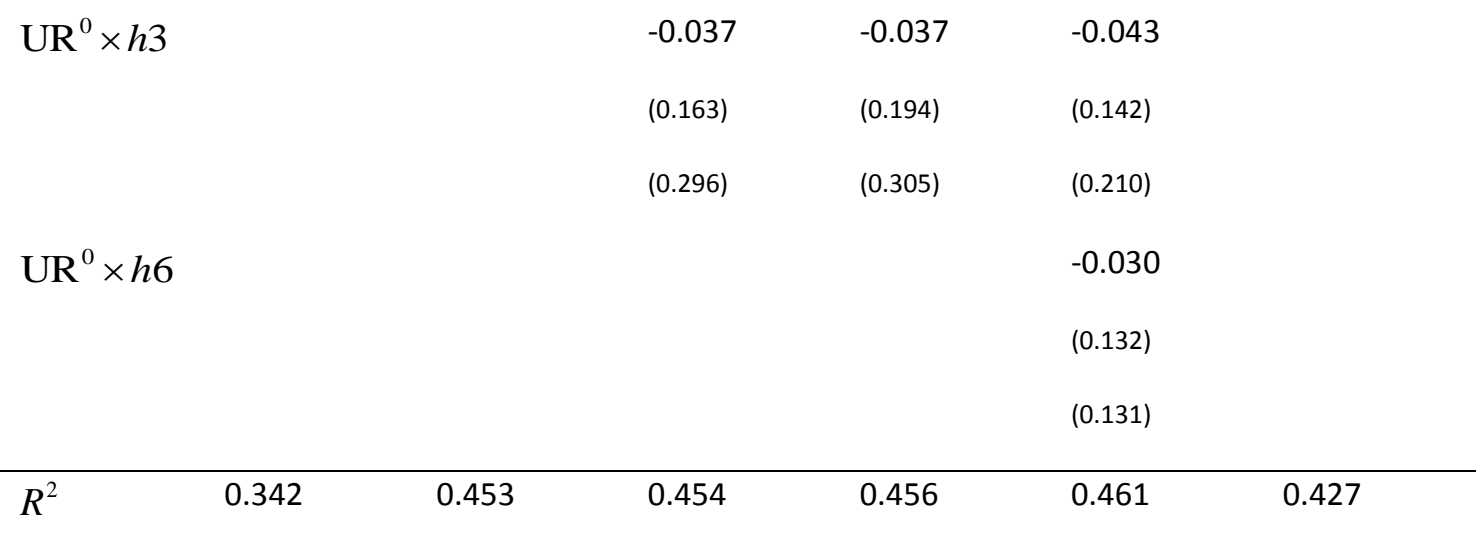

Comments to Table 2:

1) HAC $p$-values and MBB $p$-values for the two blocks bootstrap are given in brackets beneath the parameter estimates in the first and second rows respectively.

2) * indicates 5\% significance according to the OLS HAC standard errors and Student- $t$ ratios.

3) + indicates $5 \%$ significance according to MBB standard errors.

4) Country effects are jointly significant in all models. Therefore they are not included in the table.

The relevance of using the MBB covariance matrix for computing the Student- $t$ statistics is shown by the results obtained for $\mathrm{UR}^{0} \times h 1$, which indicates the individual cross-effect of the onestep ahead forecast. Although its coefficient is not large and, judging by the HAC estimates of its standard error, not significant, it knots together the nonlinear dependencies of the model. Its removal in Model 6 changes substantially the estimates of the remaining parameters of the model and, most notably, biases the value of $\beta$ towards zero. It is interesting to note that this is the only variable across the specifications which is significant according to the MBB estimates of the covariance matrix and not the $\mathrm{HAC}$ results. With $\mathrm{UR}^{0} * h 1$ present, cross effects of other forecast horizons and $\mathrm{UR}_{i, h}^{0}$, except $\mathrm{UR}^{0} * h 2$, are not significant (these results are equally not reported here).

\section{SUMMARY OF THE ROBUSTNESS ANALYSIS}

The empirical estimates of the uncertainty distributions and the CURE-convergence model have been examined for robustness. In particular, it has been evaluated whether (i) the fact that the parameter $\rho$ in equation (3) has been fixed at $\rho=0.75$ affects the accuracy of estimation of the 
WSN distribution; (ii) the choice of a particular type of minimum distance measure in the estimation distorts the results; (iii) the fit of the WSN distribution is admissible in comparison with other distributions used for approximating forecast errors and (iv) the use of the scaled forecast errors in the estimation rather than unscaled errors affects the results of the CURE-convergence test. Numerical results of the robustness analysis are given in the On-line Annex, Part B, and summarised below.

Regarding $(i)$, it is shown that the separately estimated parameter $\rho$ is very close to 0.75 , and that its mean across countries for most of the forecast horizons is not significantly different from 0.75 at the $5 \%$ significance level. Moreover, the estimates of $\rho$ for the entire euro area for different forecast horizons are also reasonably close to 0.75 . This justifies the choice of $\rho=0.75$ for the empirical analysis.

Regarding (ii), it is shown that in most cases, when parameters $a$ and $b$ are not too close to zero, the average differences between the estimates obtained by applying different criteria, do not exceed $10 \%$ of their mean.

Regarding (iii), a comparison has been made with two other different distributions used for approximating distributions of forecast inflation uncertainty, these being the two-piece normal distribution, which is often used by practitioners in central banks (see e.g. Tay and Wallis, 2000) and the generalised beta (see e.g. Clements, 2014; Kenny and Melo Fernandes, 2016).

The goodness of fit of all these distributions varies in the sense that it is difficult to say decisively which of them is better. Overall, the WSN for the scaled data, where forecast errors are defined by (2), seems to exhibit the best fit for shorter forecast horizons. For the non-scaled data, where $u_{t, h}=e_{t+h \mid t}$, the advantage of WSN over other distributions is more evident for all forecast horizons. Nevertheless, the differences between the minimum distance measures for all these distributions are relatively small. 
Regarding (iv), The CURE-convergence model has been replicated with the unscaled errors used for the computations of the $g_{i, h}$ and $\mathrm{UR}_{i, h}$ variables. Models based on the scaled and unscaled errors give similar results in terms of interpretation. As expected, the coefficient of determination for the 'unscaled' model is much greater that for the 'scaled' model, reflecting the spurious effect of the time-dependent variation that is typical for unscaled errors when there is a significant second-order dependence (e.g. GARCH).

\section{CONCLUSIONS}

The results of this paper are quite supportive of Issing's 'one size fits all' conjecture, albeit not in the absolute sense. There are clearly no signs of homogeneity being achieved in inflation uncertainty across the euro area countries. This is not only a case of Greece versus the rest of the euro area, as it also applies to more stable countries like France and Italy. Fiscal and institutional discrepancies within the Union are still too large for this sort of convergence. As found by Rossi and Sekhposyan (forthcoming), the idiosyncratic effects on inflation uncertainty still exist and might even cause divergence in it. However, it is argued here that without the monetary policy of the ECB this divergence would have been worse. The CURE-convergence, which is the tendency of the relative ECB policy effects on inflation uncertainty to be unified across countries, is clearly detected. This may be a sign of institutional adjustment and also of some effectiveness in monetary policy. At the same time, the results presented here do not confirm the Arnold and Lemmen (2008) conjecture that inflation uncertainty across the euro area countries is negatively related to the degree of their influence on ECB policy. On the contrary, this paper provides statistical evidence for the long-run tendency of the ECB's monetary policy to affect inflation uncertainty in all countries in an equal way, regardless of their influence.

On the methodological side, the paper uses a cross-section model which exhibits heterogeneity similar to that of the fixed effects panel data models and can be used for analysing forecast effects jointly for different horizons. However, the stochastic structure of such models can 
be quite complicated and might require the application of methods that allow for nonlinear dependence. The two-step method applied here for estimating the forecasting model first and then analysing the distributions of forecast errors is a novel approach, though it might not be the most efficient. However, the joint estimation of the ARIMA-GARCH model with skew-normal uncertainty still poses some statistical questions, which have not yet been fully resolved.

\section{REFERENCES}

Abel, J., R. Rich, J. Song and J. Tracy (2016), 'The measurement and behavior of uncertainty: evidence from the ECB survey of professional forecasters' Journal of Applied Econometrics, 31, 533-550.

Al-Nowaihi, A. and S. Dhami (2014), 'Foundations and properties of time discount', University of Leicester Department of Economics Working Paper 14/11.

Andrade, P. and H. Le Bihan (2013), 'Inattentive professional forecasters', Journal of Monetary Economics 60, 967-982.

Arnold, I.J.M. and J.J.G. Lemmen (2008), 'Inflation expectations and inflation uncertainty in the Eurozone: evidence from survey data', Review of World Economics 144, 325-345.

Ball, L. (1992), 'Why does higher inflation raise inflation uncertainty?', Journal of Monetary Economics 29, 371-378.

Baker, S.R., N. Bloom and S.J. Davis (2015), 'Measuring economic policy uncertainty', Quarterly Journal of Economics 136, 1593-1636.

Barro R.J. and X. Sala-i-Martin (1995), Economic Growth, McGraw Hill, New York.

Belke, A. and D. Kronen (2015), 'Exchange rate bands of inaction and play-hysteresis in Greek exports to the euro area, the US and Turkey - sectoral evidence', Ruhr Economic Papers No. 593. 
Bjørnland, H.C., K. Gerdrup, A.S. Jore, C. Smith and L.A. Thorsrud (2012), 'Does forecast combination improve Norges Bank inflation forecasts?', Oxford Bulletin of Economics and Statistics 74, 163-179.

Bloom, N. (2014), 'Fluctuations in uncertainty', Journal of Economic Perspectives 28, 153176.

Bomberger, W.A. (1999), 'Disagreement and uncertainty', Journal of Money, Credit and Banking 31, 273-276.

Buelens, C. (2012), 'Inflation forecasting and the crisis: assessing the impact of the performance of different forecasting models and methods', European Economy, European Commission, Economic Papers 451.

Busetti, L. Forni, A. Harvey and F. Venditti (2007), 'Inflation convergence and divergence within the European Monetary Union', International Journal of Central Banking 3, 95-121.

Caporale, G.M. and A. Kontonikas (2009), 'The Euro and inflation uncertainty in the European Monetary Union', Journal of International Money and Finance, 28, 954971.

Caporale, G.M., L. Onorante and P. Paesani (2012), 'Inflation and inflation uncertainty in euro area', Empirical Economics 43, 597-615.

Charemza, C. Díaz and S. Makarova (2015), 'Ex-post inflation forecast uncertainty and skew normal distribution. "Back from the future" approach', University of Leicester Department of Economics Working Paper 15/09.

Charemza, W., Z. Fan, S. Makarova and Y. Wang (2012), 'Simulated minimum distance estimators in macroeconomics', paper presented at the conference Computational and Financial Econometrics, Oviedo. 
Clark, T.E. and T. Doh (2014), 'Evaluating alternative models of trend inflation', International Journal of Forecasting 30, 426-448.

Clark, T.E. and F. Ravazzolo (2015), 'Macroeconomic forecasting performance under alternative specification of time-varying volatility', Journal of Applied Econometrics $30,551-575$.

Clements, M.P. (2014), 'Forecast uncertainty - ex ante and ex post: US inflation and output growth', Journal of Business and Economic Statistics 32, 206-216.

Clements, M.P. (2015), 'Assessing the evidence of macro-forecaster herding: forecasts of Inflation and output growth', presented at workshop The Economic Value of Macroeconomic Forecasts with Big Data, University of Warwick.

Chowdhury, K.B. and N. Sarkar (2013), 'Friedman-Ball hypothesis revisited in the framework of regime based model for inflation: evidence from G7 and some Euro Zone countries', Indian Statistical Institute, Discussion Paper 03/2013.

Cukierman, A. and A. Meltzer, A (1986), 'A theory of ambiguity, credibility, and inflation under discretion and asymmetric information', Econometrica 54, 1099-1128.

Davig, T., E.M. Leeper and T.B. Walker (2011), 'Inflation and the fiscal limit', European Economic Review 55, 31-47.

Delrio, S. (2016), 'Estimating the effects of global uncertainty in open economies', University of Venice mimeo.

Estrada, Á., J. Galí, and D. López Salido (2013), ‘ Patterns of convergence and divergence in the Euro area', IMF Economic Review 61, 601-630.

European Commission (2015), 'European economic forecast, Spring 2015', European Economy 2/2015.

Fisher, S. (1977), 'Long-term contracts, rational expectations, and the optimal money supply rule', Journal of Political Economy 85, 191-205. 
Friedman, M. (1977), 'Nobel lecture: inflation and unemployment', Journal of Political Economy 85, 451-472.

Giordani, P. and P. Söderlind (2003), 'Inflation forecast uncertainty', European Economic Review 47, 1037-1059.

Golob, J.E. (1994), 'Does inflation uncertainty increase with inflation?', Economic Review, Federal Reserve Board of Kansas City, 27-38.

Gonçalves, S. (2011), 'The moving blocks bootstrap for panel linear regression models with individual fixed effects', Econometric Theory 27, 1048-1082.

Henzel S.R. and M. Rengel (2017), 'Dimensions of macroeconomic uncertainty: a common factor analysis', Economic Inquiry, 55, 843-877.

Islam N., (1995), 'Growth empirics: A panel data approach', Quarterly Journal of Economics 4, 1127-1170.

Issing, O. (2001), 'The single monetary policy of the European Central Bank: one size fits all', International Finance 4, 441-462.

Issing, O. (2005), 'One size fits all! A single monetary policy for the euro area', speech at the International Research Forum, Frankfurt am Main,

https://www.ecb.europa.eu/press/key/date/2005/html/sp050520.en.html .

Jurado, K., S.C. Ludvigson and S. Ng (2015), 'Measuring uncertainty', American Economic Review 105, $1177-1216$

Lahiri, K., H. Peng and X. Sheng (2014), 'Measuring uncertainty of a combined forecast', presented at the workshop Uncertainty and Economic Forecasting, UCL, London.

Lahiri K, and X. Sheng (2010), 'Measuring forecast uncertainty by disagreement: the missing link', Journal of Applied Econometrics 25, 514-538. 
Lopez, C. and D.H. Papell (2012), 'Convergence of Euro area inflation rates', Journal of International Money and Finance 31, 1440-1458.

Makarova, S. (2014), 'Risk and Uncertainty: Macroeconomic Perspective', UCL SSEES Economic and Business Working Paper No. 129.

Mitchell, J., D. Robertson and S. Wright (2015), 'What univariate models can tell us about multivariate macroeconomic models?', presented at WBS/Monash Workshop, the University of Warwick.

Monfort, M., J.C. Cuestas and J. Ordóñez (2013), 'real convergence in Europe: a cluster analysis', Economic Modeling 33, 689-694.

Mongelli, P.P. and J.L. Vega (2006), 'What effects is EMU having on the Euro area and its member countries? An overview', Proceedings of the June 2005 workshop, European Central Bank, Working Paper No. 599.

Morris, S. and H.S. Shin (2002), 'Social value of public information', American Economic Review 92, $1521-1534$.

Orphanides, A. and J.C. Williams (2005), 'Inflation scares and forecast-based monetary policy', Review of Economic Dynamics 8, 498-527.

Patton, A.J. and A. Timmermann (2010), 'Why do forecasters disagree? Lessons from the term structure of cross-sectional dispersion', Journal of Monetary Economics 57, 803-820.

Phelps, E.S. and J.B. Taylor (1977), 'Stabilizing powers of monetary policy under rational expectations', Journal of Political Economy 85, 163-190.

Rossi, B. and T. Sekhposyan (2015), 'Macroeconomic uncertainty indices based on nowcast and forecast error distribution', American Economic Review: Papers and Proceedings 105, 650655. 
Rossi, B. and T. Sekhposyan (forthcoming), 'Macroeconomic Uncertainty Indices for the Euro Area and its Individual Member Countries', Empirical Economics.

Rossi, B., T. Sekhposyan and M. Soupre (2016), 'Understanding the sources of macroeconomic uncertainty', ICREA-University of Pompeu Fabra mimeo, http://www.econ.upf.edu/ brossi/RossiSekhposyanSoupre.pdf .

Stock, J.H. and M.W. Watson (2007), 'Why has U.S. inflation become harder to forecast?', Journal of Money, Credit and Banking 39 (Supplement), 1-33.

Vavra, J. (2014), 'Inflation dynamics and time-varying volatility: new evidence and an Ss interpretation', The Quarterly Journal of Economics 129, 215-258.

\section{APPENDIX A.}

Data description.

Data source: Eurostat. For all countries, the last observation is in November 2014.

Of the 18 countries in the euro area, Cyprus and Slovakia were the only two countries for which the maximum likelihood ARIMA-GARCH model estimation failed and no convergence was achieved. Therefore these countries have been excluded, so the number of countries considered is 16 .

The common date for all countries for which $\mathrm{UR}_{i, 1}$ is computed (the date of $\mathrm{UR}_{i, 1}^{0}$ ) is December 2010. That means the date for $\mathrm{UR}_{i, 2}^{0}$ is January 2011 etc.

Note that the RMSEs are computed using moving windows of $\Delta=120$. Therefore the number of observations for each country in columns (5) and (6) in Table A1 differs by 118.

TABLE A1.

Description of data spans and recursions. 


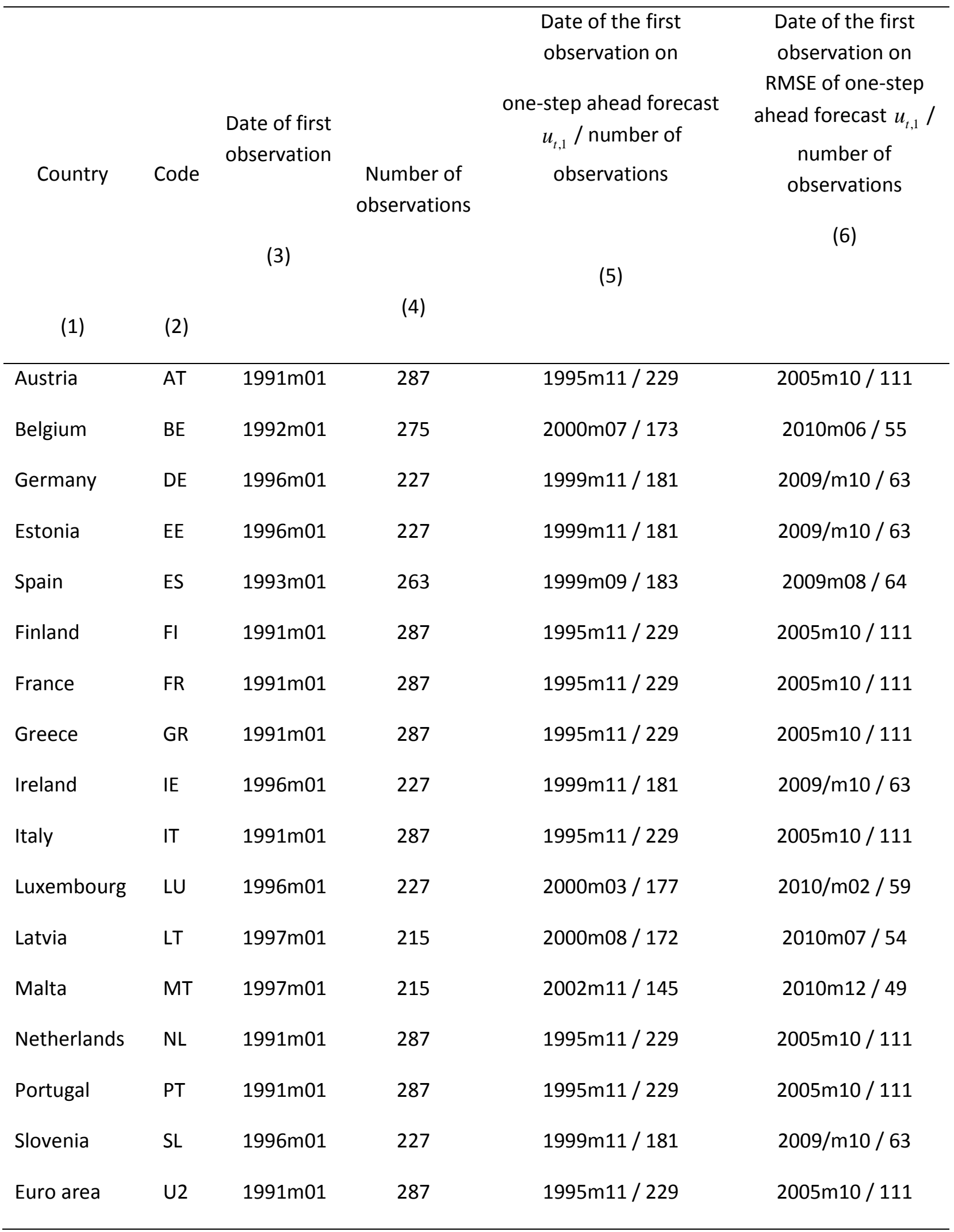

APPENDIX B.

Description of the simulated minimum distance estimation method 
The simulated minimum distance method (SMDE) estimates of a vector of parameters $\omega$ ( $\omega \in \Omega \subset \mathbb{R}^{k}$ ), introduced by Charemza et al., (2012), are given by:

$$
\hat{\omega}_{n}^{S M D E}=\underset{\omega \in \Omega}{\arg \min }\left\{\mu_{w}\left(d\left(g_{n}, f_{t, \omega}\right)\right)_{r=1}^{R}\right\},
$$

where $f_{t, \omega}$ is the approximation of the $p d f, f_{\omega}$, of a random variable obtained by generating $r=1, \ldots, R$ replications (drawings) from a distribution with the parameters $\omega ; g_{n}$ denotes the density of the empirical sample of size $n ; \mu_{w}$ is an aggregation operator based on $R$ replications, which deals with the problem of the 'noisy' criterion function (median, in this case); and $d(\bullet, \bullet)$ is the distance measure. This approach is similar to that of Dominicy and Veredas (2013).

Following Cressie and Read (1984), the distance measure for data organised in a histogram with $m$ cell, is defined as:

$$
d\left(g_{n}, f_{t, \omega}\right)=\frac{1}{\lambda_{C R}\left(\lambda_{C R}+1\right)} \sum_{i=1}^{m+1} g_{n}(i)\left[\left(\frac{g_{n}(i)}{f_{t, \omega}(i)}\right)^{\lambda_{C R}}-1\right] .
$$

For $\lambda_{C R}=1$ formula (B2) gives the Pearson's $\chi^{2}$ measure, for $\lambda_{C R}=-1 / 2$ the Hellinger twice squared distance $(H D)$ and for $\lambda_{C R}=-2$ the Neyman $\chi^{2}$ measure. For $\lambda_{C R} \rightarrow 0$ the continuous limit of the right-hand side expression in (B2) gives the likelihood disparity. Although the minimum distance estimators have been computed for all the $\lambda_{C R}$ 's listed above, for further inference it has been decided to concentrate on the $H D$ distance estimator. Its properties have been well researched in the context of skew normal distributions (see Greco, 2011), and it is known that it is reasonably robust to the presence of outliers, which might appear in a large sample of inflation forecast errors, especially for longer forecast horizons. For more details see e.g. Basu, Shioya and Park, (2011). The On-line Annex, Part B contains results of the robustness analysis with respect to the choice of measure. 
Due to the nonlinear nature of (3), the minimisation criteria and the constraints imposed, the function in (B1) has been minimised using the grid search algorithm (for a review and comparison of numerical techniques in grid search see e.g. Jiménez, Lázaro and Dorronsoro, 2009). Denoting the number of grids (for each of the estimated parameters) by _ $n$, the maximum depth of grid by_d, and the initial length of the interval where the particular parameter is searched by $\_I_{0}\left(\_n\right.$ and $\_d$ are identical for all parameters) gives the length _ $I$ of the last interval, giving the precision of the estimation, as $\_l={ }_{-} l_{0}\left(\_n-1\right)^{-{ }^{d} d}$. This secures the accuracy of the minimisation if only the initial intervals are properly established.

For the parameters $a$ and $b$, the initial search intervals are of length 2 and for $\sigma$ the length is 3.99. For $\_n=7$ and $\_d=20$ this gives the maximal precision of the search equals to $1.82 \mathrm{e}-12$ for $a$ and $b$, and 3.63e-12 for $\sigma$.

In practice, however, the accuracy of minimisation can be affected by the appearance of cells with zero frequency in the empirical histogram, which can result from a combination of small sample size and the presence of outliers. The algorithm sets the number of cells automatically, with the lower constraint on the number of cells equal to 9. Although the Mandal, Basu and Pardo (2010) empty cells penalty is implemented in the algorithm, the appearance of a substantial number of empty cells affects the estimation. Because of that, it has been decided to limit the maximum forecast horizon to 18 in the computation of the CURE-convergence test, as for longer horizons where there are fewer observations in the sample, the number of empty cells becomes significant and the fit is generally worse due to appearance of outliers.

Another problem arises because the criterion function (B1), where the entries are simulated, is 'noisy', so that an accidental extremum can be obtained outside the true extremum due to the stochastic nature of the observations (see e.g. Spall, 2003). In order to safeguard against this, each search was repeated 50 times and the median result was chosen. 


\section{References to Appendix B}

Basu, A., H. Shioya and C. Park (2011), Statistical inference. The minimum distance approach, CRC Press.

Cressie, N. and T.R.C. Read (1984), 'Multinomial goodness-of-fit tests', Journal of Royal Statistical Society Series B, 46, 440-464.

Dominicy, Y. and D. Veredas (2013), 'The method of simulated quantiles', Journal of Econometrics 172, 233-247.

Greco, L. (2011), 'Minimum Hellinger distance based inference for scalar skew-normal and skew-t distributions', Test 20, 120-137.

Jiménez, A., B., J.L. Lázaro and J.R. Dorronsoro (2009), 'Finding optimal model parameters by deterministic and annealed focused grid search', Neurocomputing $\mathbf{7 2}, \mathbf{2 8 2 4 - 2 8 3 2 .}$

Mandal, A., A. Basu and L. Pardo (2010), 'Minimum disparity inference and the empty cell penalty: asymptotic results', Sankhyā: The Indian Journal of Statistics 72-A, part 2, 376-406.

Spall, J. C. (2003), Introduction to stochastic search and optimization: estimation, simulation and control, Wiley, Hoboken.

\section{APPENDIX C}

Formula for computing the uncertainty ratio UR.

For the WSN random variable defined by (3), the corresponding uncertainty ratio can be explicitly expressed via its parameters as

$$
\mathrm{UR}=1+2 \frac{\rho\left[|a| D_{m, \sigma}+|b| D_{k, \sigma}-\rho / 2\right]-[a \varphi(m / \sigma)-b \varphi(k / \sigma)]^{2}}{1-2 \rho\left(|a| D_{m, \sigma}+|b| D_{k, \sigma}\right)+W_{m, k, \sigma} \cdot\left(|a| D_{m, \sigma}+|b| D_{k, \sigma}\right)^{2}}
$$


where $\varphi$ and $\Phi$ denote respectively the density and cumulative distribution functions of the standard normal distribution, $D_{x, \sigma}=\int_{|x / \sigma|}^{+\infty} t^{2} \varphi(t) d t$ and

$$
W_{m, k, \sigma}=\left[D_{m, \sigma} \varphi^{2}(k / \sigma)+D_{k, \sigma} \varphi^{2}(m / \sigma)\right] /\left[D_{m, \sigma} \varphi(k / \sigma)+D_{k, \sigma} \varphi(m / \sigma)\right]^{2} .
$$

The derivation of this formula and some analytical properties of the UR are discussed in Charemza, Díaz and Makarova (2015). 